\title{
SOME PRELIMINARY NOTES ON THE GENUS EPHEMERELLA
}

\author{
By ANNe LOUISE STEGer
}

Cornell University, Ithaca, N. Y.

In an attempt to fill in some of the gaps left by Miss Anna H. Morgan in her study of the Mayflies of Fall Creek in 1911 (Ann. Ent. Soc. Am. 4:93-119), some rearing and collecting work was carried on during the summer of 1930 at Cornell University under the direction of Dr. Needham with the genus Ephemerella. As a result I was able to obtain stages of several of the local species which had not as yet been taken or described. Following is a table of the local species taken, indicating those stages which had already been described $(D)$ and those which had not, and which were collected last summer $(U)$ :

\begin{tabular}{|c|c|c|c|c|c|}
\hline \multirow[t]{2}{*}{ Species } & \multirow[t]{2}{*}{ Nymph } & \multicolumn{2}{|c|}{ Subimago } & \multicolumn{2}{|c|}{ Imago } \\
\hline & & $\hat{o}$ & 우 & $\hat{o}$ & 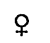 \\
\hline 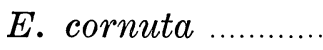 & $\ldots \quad \mathrm{D}$ & $\mathrm{D}$ & $\mathrm{U}$ & $\mathrm{U}$ & \\
\hline E. deficiens & $\mathrm{D}$ & $\mathrm{D}$ & $\mathrm{D}$ & $\mathrm{D}$ & \\
\hline E. dorothea & $\mathrm{D}$ & $\mathrm{U}$ & $\mathrm{U}$ & $\mathrm{D}$ & \\
\hline E. rotunda & $\mathrm{D}$ & $\mathrm{U}$ & $\mathrm{D}$ & $\mathrm{U}$ & \\
\hline E. septentrionalis & $\mathrm{U}$ & $\mathrm{U}$ & $\mathrm{U}$ & $\mathrm{D}$ & \\
\hline
\end{tabular}

The rearing of the nymphs to the subimago and imago stages was carried on in a deserted pump house on Beebe Lake, where it was possible to have a constant supply of fresh water running through the troughs. The nymphs were collected in streams by means of a small wire hand screen, brought home and put into wire cages in the troughs, after having been properly identified and separated according to species. The cages were labelled with 
name of species and collecting data, and were visited once or twice a day in order to catch the subimagos as they crawled out of the water onto the part of the cage above water. The subimagos were then put into paper bags, which were labelled as to species, date of collecting and date of subimago transformation. The paper bag, because of the roughness of its surface, offers an excellent place for the imago to crawl out of its subimago skin. The paper bags were investigated each day, also, in order to get the imago as soon after transformation as possible. As a result, all stages of the above-listed species were obtained, and some observations made on the relative length of time of subimaginal transformations. For the most part, the males in all species reared seemed to require slightly more time than the females for this last molt.

The collecting was done in the streams around the general vicinity of Ithaca. Fall Creek borders the campus on the north and collections were made in it at various points from the campus to Freeville, a small town about eight miles northeast of Ithaca. Cascadilla Creek borders the campus on the south, collecting being done in it upstream over a distance of about three miles. Further collecting was done in Salmon Creek ten miles northeast of Ithaca, in Van Buskirk's Glen ten miles to the south, in Slaterville Wild Flower Preserve fifteen miles to the east, in Six Mile Creek two miles to the south, in North Harford Brook (Cortland County) twenty to twenty-five miles to the northeast, in North Spencer Stream about fifteen miles south, in Enfield Glen seven miles to the south, and in Otter Creek which borders on the southwest of Cortland, N. Y.

\section{Ephemerella cornuta Morgan}

\section{Male imago:}

Measurements : body $10 \mathrm{~mm}$., tails $11 \mathrm{~mm}$., fore leg 9.5 $\mathrm{mm}$., fore wing $9 \mathrm{~mm}$., hind wing $2.5 \mathrm{~mm}$. Eyes and ocelli dark brown; antennæ light-brown. Thorax a uniform dark brown. Abdomen a rather light gray-brown. Wings hyaline, brownish at the bases. Axillary cords of the fore 


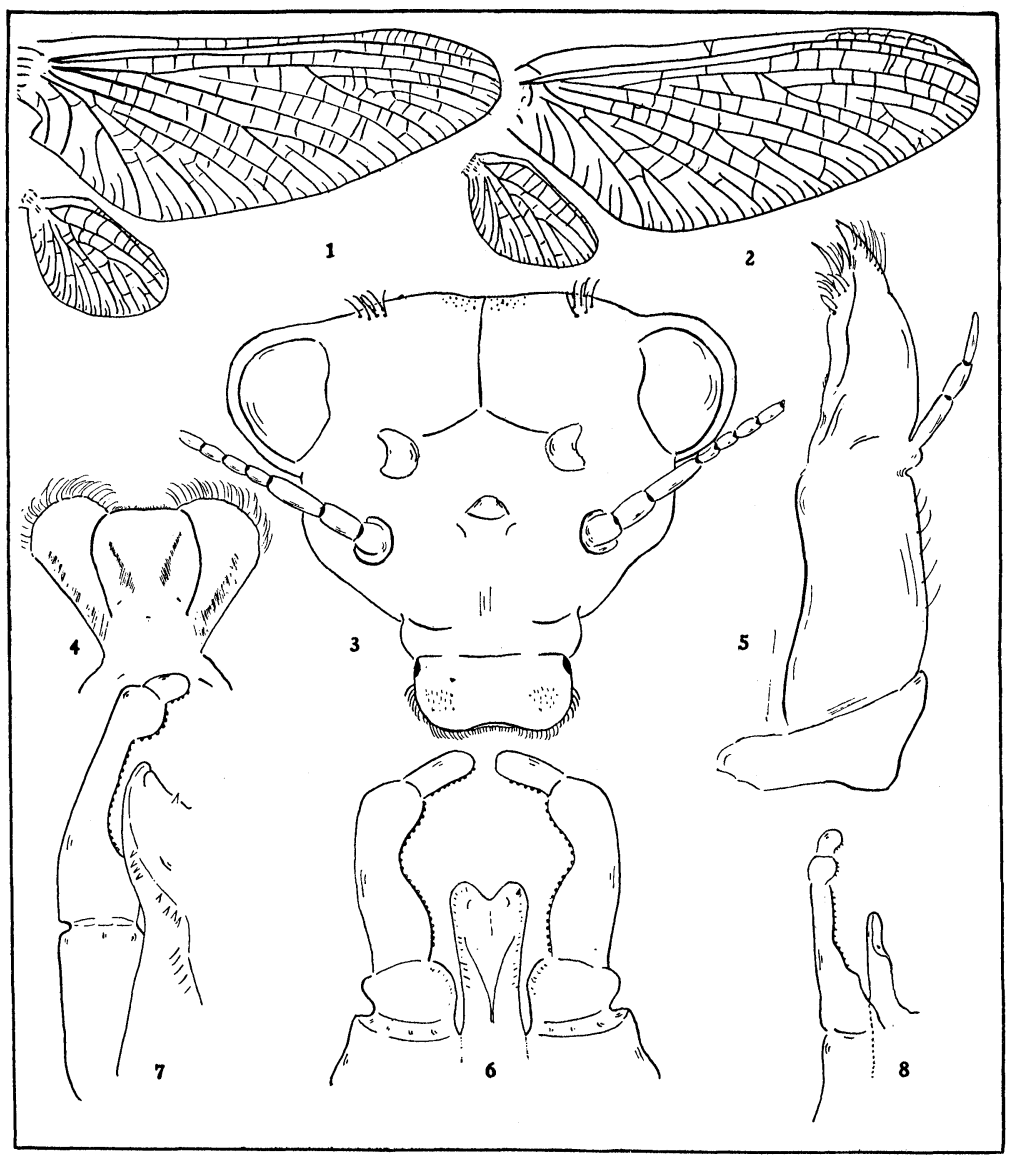

Fig. 1.

1. E. septentrionalis - wings of adult;

2. E. cornuta-wings of adult;

3. E. septentrionalis - head of nymph;

4. E. septentrionalis-hypopharynx;

5. E. septentrionalis - maxilla;

6. E. cornuta-forceps and penes of adult;

7. E. rotunda-forcep and penis of adult;

8. E. septentrionalis - forcep and penis of adult. 
wing extending backward on each side of the median lobe of the metathorax, in slender points. Tails three, whitish. Last segment of the forceps rather elongate, not bulbous; second segment with a rather bulbous swelling at each end.

\section{Female imago:}

Measurements : body $9 \mathrm{~mm}$., forewing $10 \mathrm{~mm}$., hindwing $3 \mathrm{~mm}$. Color of thorax a dark brown similar to that of the male. Abdomen a slaty-gray, due probably to the egg mass which showed through.

\section{Subimago:}

Wings smoky in color. This nymph was taken as early as May 16th in North Harford Brook. It was found in greatest abundance and maturity in a small swift stream near North Spencer on May 23rd. This last stream contains many small flat rocks on its mud bottom, and the nymphs were with difficulty distinguished from the mud-clumps on the undersides of these rocks. By June 5th they had practically disappeared from this stream, only a few good-sized nymphs and many cast skins being found. They were likewise observed in great numbers in Salmon Creek (in a similar section of the stream) on July 6th, but were gone from here by July 13th-indicating that week to have been the height of their season in that particular stream. They were collected by Dr. Needham as late as August 30th, in Elk River, West Virginia. The nymphs were fairly common in Cascadilla Creek, Slaterville, and North Spencer.

\section{Ephemerella deficiens Morgan}

The nymphs taken of this species were very black with a light mid-dorsal line extending from the anterior margin of the prothorax to the posterior margin of the metathorax. The gills, tibiæ and tarsæ are white. In alcohol the blackness of the body fades into a dark brown, and the light middorsal line becomes almost indistinguishable. 
Mature nymphs were first taken in the shallowest and most rapid waters of Cascadilla Creek on June 8th. Many full-grown nymphs were obtained from Salmon Creek in a similar sort of habitat on July 6th, and were gone from this stream by July 13th. They were collected as late as August 3rd in Fall Creek.

The subimago of E. deficiens is very dark in color, the wings being smoky.

\section{Ephemerella dorothea Needham}

\section{Imago:}

The imagos reared seem to be $1-3 \mathrm{~mm}$. larger than those of Dr. Needham's original description ${ }^{1}$ - the average body length of the male being $7-8 \mathrm{~mm}$., of the female $8 \mathrm{~mm}$. The ocelli of both male and female imagos are ringed at their bases with black.

\section{Subimago:}

The wings of the subimago are subhyaline in color with a tendency to turn black around the edges just before the subimaginal molt.

\section{Nymph:}

The nymph is much like $E$. rotunda in general appearance, although smaller and without dorsal spines. The two were frequently found associated together amongst the vegetation and moss accumulated around the stones of fairly rapidly flowing streams. The seasonal height in abundance and maturity of $E$. dorothea, however, seems to be a few weeks later than that of $E$. rotunda-the former being in its height in early June when the latter had already begun to disappear. The nymphs were collected as early as May 23rd in the North Spencer Stream, and were found to be fairly common (though never as much so as $E$. rotunda) in most of the local streams.

\footnotetext{
${ }^{1}$ N. Y. State Mus. Bull. 1908, 124: 190.
} 


\section{Ephemerella rotunda Morgan}

Male adult: (reared from nymphs collected in Cascadilla Creek, Salmon Creek, Otter Creek, Van Buskirk's Glen, North Harford Brook, North Spencer Stream and Fall Creek).

Measurements : Body $9 \mathrm{~mm}$., tails $12 \mathrm{~mm}$., foreleg $9 \mathrm{~mm}$., fore wing $10 \mathrm{~mm}$. Head light brown; compound eyes orangebrown. Thorax and abdomen a shiny medium brown. Legs yellowish or tan. Tails ringed with dark brown at the base of each segment. Axillary cords of the fore wing prolonged into slender spines projecting posteriorly on either side of the hinder lobe of the mesothorax. Wings hyaline. Penes with stout spines.

Subimago: Wings subhyaline.

Nymph: (dark variety).

(Taken in Cascadilla Creek, Otter Creek, Salmon Creek.)

Measurements : body $9-10 \mathrm{~mm}$; tails $6 \mathrm{~mm}$. Head smooth and round; labium grayish in color. Thorax broad and flaring, the wing pads descending well over the first several abdominal segments; frontal angles of the prothorax with a prominent tooth, lateral margins with a broad thin shelflike edge; front angles of the mesothorax with a prominent triangular tooth. Posterior angles of the head forming almost right angles. General color of abdomen blackishbrown, segments 5, 6 and 7 yellowish in color. Dorsal spines very well developed, occurring on segments 2-9. Lateral margins of segments 3-9 acuminate and slightly incurving, acuminate but not incurving on 10. Legs short and stubby relative to body; yellowish in color, the tibia and tarsus with dark brown bands. Gills present on abdominal segments $3-7$, the 7 th gill almost completely covered by the 6th. Tails lightish with several slightly darker bands, and with circlets of stiff hairs at the bases of the segments; fringed with longer hairs for the last two-thirds of their length. These longer hairs gradually diminish in length 
toward the tips of the tails, which appear practically hairless.

Nymph: (light variety).

(Taken in Cascadilla Creek, Salmon Creek, Otter Creek, Van Buskirk's Glen, North Harford Brook, and North Spencer Stream.)

Measurements : body $10 \mathrm{~mm}$., tails $6 \mathrm{~mm}$. Head and body rounded and smooth. Posterior angles of head indrawn. Labium not marked with grayish as in the dark variety. General color light brown, tibia and tarsus banded with light brown. Front angles of the prothorax only slightly rounded, lateral margins only slightly flaring. Dorsal spines present on segments 4-9, but not so well developed as in the dark variety. Sometimes very slight spines can be detected on segments 2 and 3. Gills present on segments $3-7$, the 7 th gill not being so completely covered by the 6 th as in the dark variety.

I do not feel that these two are different species, but regard them merely as color varieties of $E$. rotunda. The differences seem to be a matter of degree, with intergradations of such characters as the prominence of the dorsal spines, the extent to which the 6th gill covers the 7 th, the toothing of the prothorax and metathorax, and the flaring of the lateral prothoracic margins. This species seems to exhibit many variations in color-from the very dark variety described above, to a light yellow variety with dark markings whose essential characters are the same.

$E$. rotunda was the most common and abundant member of the genus in the Ithaca streams from early March until late May. It was the earliest nymph collected, being found in great numbers and fully matured as early as March 16th. The last nymphs were seen in the North Harford Brook on June 11th. Although Miss Morgan and several others had never found the males of $E$. rotunda, I was able both to collect and to rear many. I did not notice any particular scarcity of males, the sexes being fairly equally distributed where the nymphs were obtainable at all. The male adults 
of the light and dark varieties showed no differences when reared, which further convinces me that they are the same species.

The nymphs of $E$. rotunda seem remarkably varied in their choice of habitat. Although most usually found in the mud-gathering moss of flat rocks on the bottoms of fairly rapid streams, they were also collected in all intergrading types of streams from shallow riffles to the rather sluggish sections of deeper streams. This variety of habitat may be in part responsible for the variety of coloration and pattern displayed by this nymph, and even for some of the minor structural differences mentioned in the above descriptions.

Ephemerella septentrionalis McDunnough

\section{Imago:}

Measurements: body $10 \mathrm{~mm}$; tails $12 \mathrm{~mm}$; foreleg of male $16 \mathrm{~mm}$., fore wing $10 \mathrm{~mm}$. (Measurements of female same, except for foreleg). Compound eyes of the male orange-brown, thorax yellowish. First seven abdominal segments grayish, 8th yellowish-gray, 9th and 10th yellow. Head, thorax and abdomen of female yellow; legs yellow. Compound eyes grayish and small; ocelli reddish-brown.

\section{Subimago:}

Wings subhyaline.

\section{Nymph:}

Measurements: body $10 \mathrm{~mm}$; tails $7 \mathrm{~mm}$; foreleg $6 \mathrm{~mm}$. Head smooth except for a tuft of hairs on either side of the mid-frontal line of the apex. General color of thorax and abdomen light brown with a narrow brown mid-dorsal line. A row of brown dots on either side the median ventral line of the abdominal segments, and one at the base of each leg on the ventral side of the thorax. Legs extremely long and slender in proportion to the body. Tarsi with a band of brown. Gills present on abdominal segments 3-7. Dorsal spines absent. Lateral spines on segments 4-9. Tails light, 
the segments surrounded at their bases with a circlet of stiff bristle-like hairs.

This nymph was collected only in North Harford Brook on May 16, 17 and 21. It had disappeared from here by June 23. It was collected from the mud-gathering roots of the vegetation along the edges of the stream in fairly great numbers, and was usually buried so deeply in the mud that it was difficult to discern and capture.

\section{HYPERASPIS PALUDICOLA SZ.}

Described from Florida. For many years I have owned a specimen doubtfully named as above, which bore the label "Provincetown, Mass.," without other information. On examining the catch of July 5, 1930, made at Dennis, Mass., I found several specimens of the same thing, and have now come to the conclusion that this is another of the many instances of the occurrence of southern species of beetles in the sand plain area of Massachusetts.

\section{HYPERASPIS DISCONOTATA MULS.}

This beetle was described from "L. Sup.," and one record appears in the N. Y. List from "Cascade. Aug."

I took one specimen by sweeping grass on June 5, 1927, and one on May 31, 1930, probably by sweeping in the same meadow in Sherborn, Mass.

C. A. Frost, Framingham, Mass. 

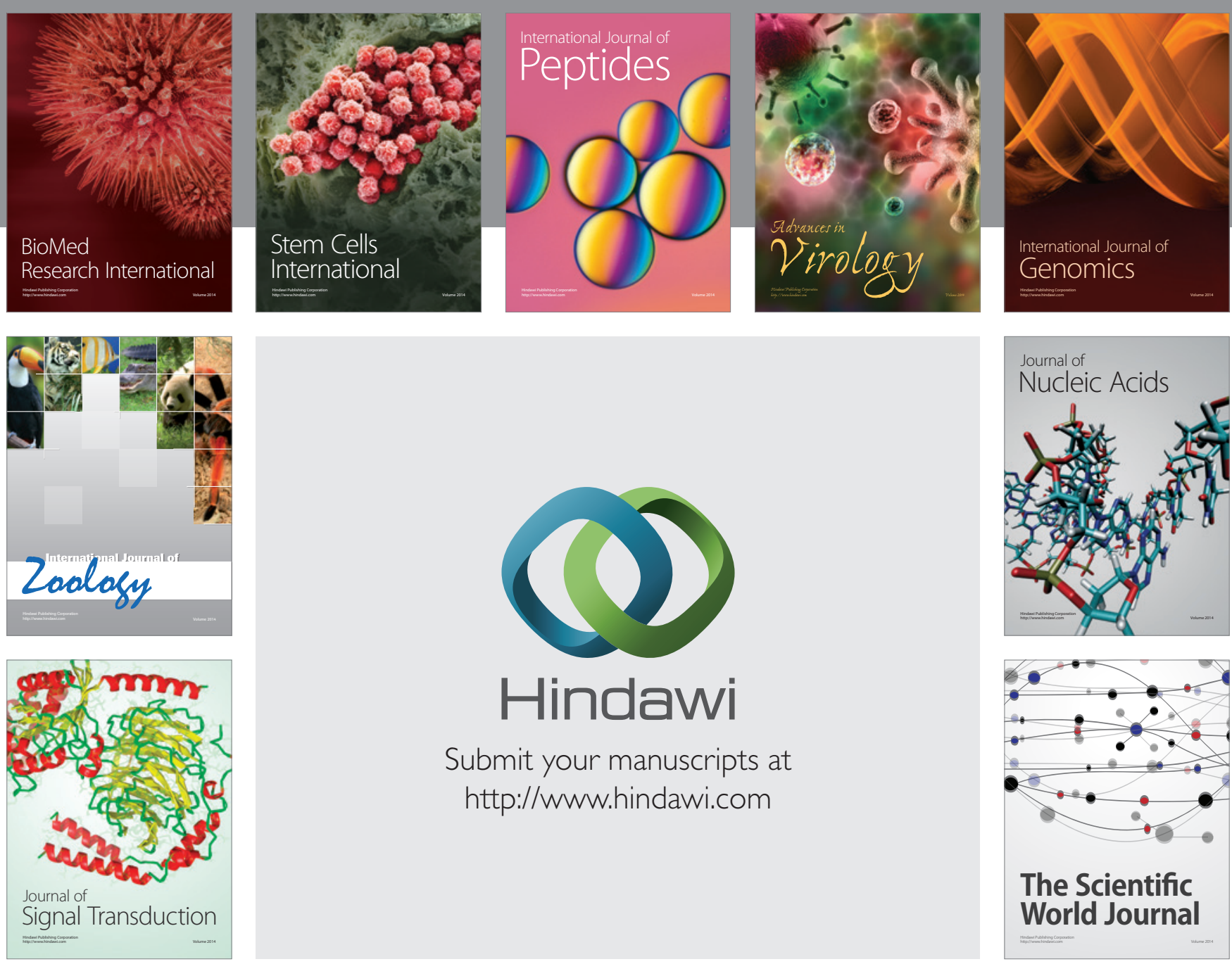

Submit your manuscripts at

http://www.hindawi.com
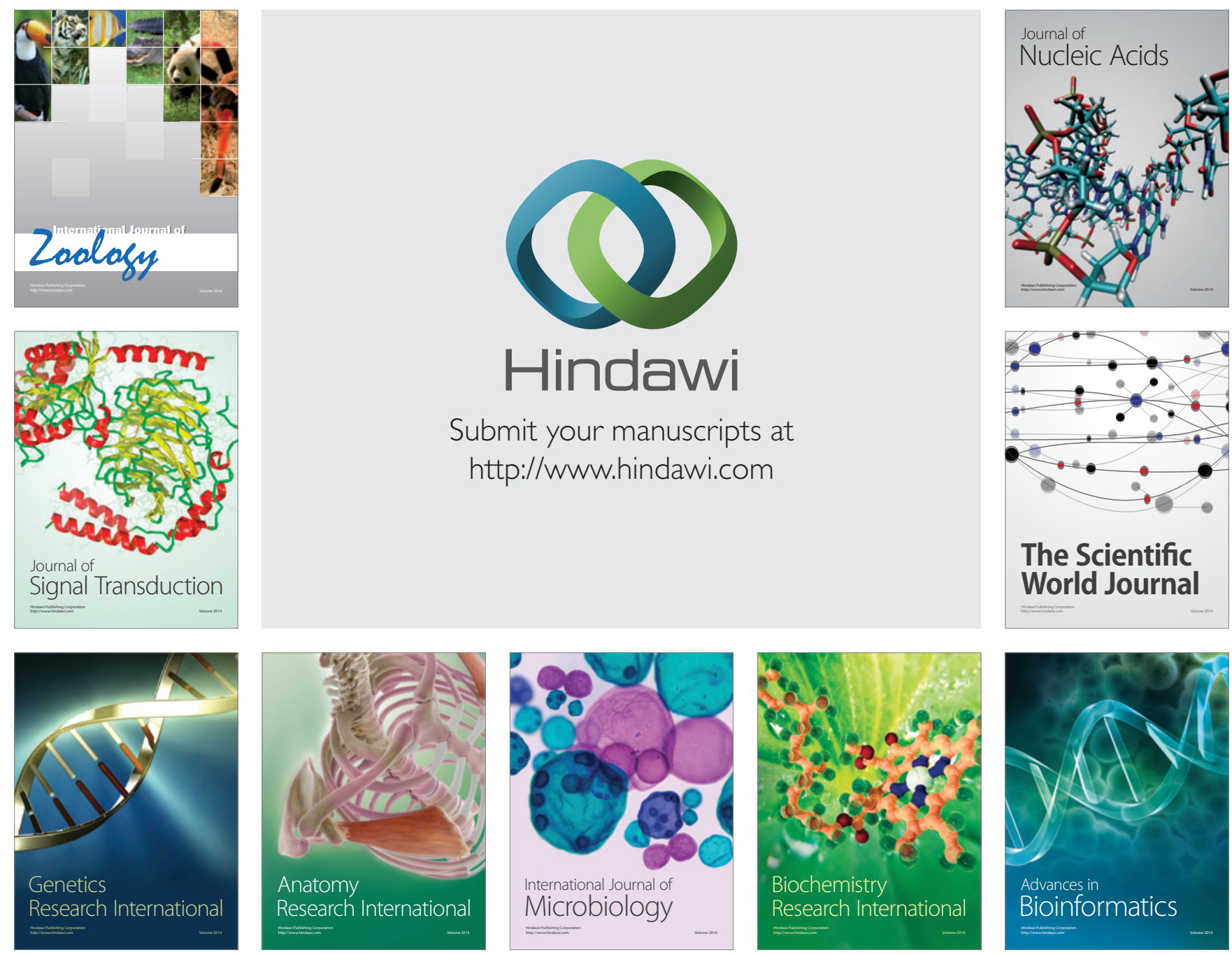

The Scientific World Journal
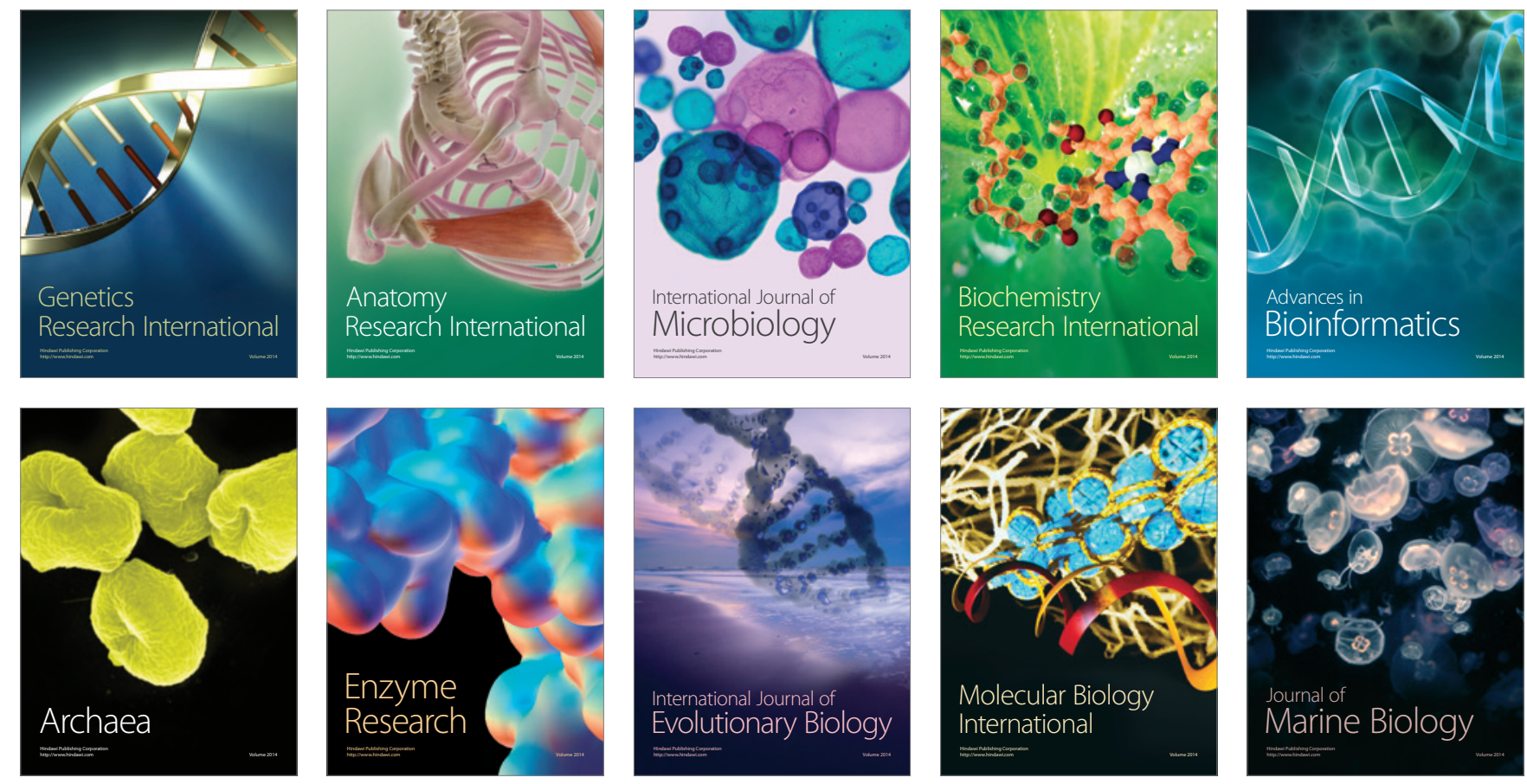